Original Research Article

\title{
Study of efficacy of ischemia reversal program (IRP) in ischemic heart disease (IHD) patients with VO2max and Duke's treadmill score
}

\author{
Rohit Sane', Varada Sugwekar ${ }^{2}$, Aarti Nadapude ${ }^{2}$, Archana Hande ${ }^{2}$, \\ Gayatri Depe ${ }^{2}$, Rahul Mandole ${ }^{1 *}$
}

${ }^{1}$ Department of Research and Development, Madhavbaug Cardiac Care Clinics and Hospitals, Mumbai, Maharashtra, India ${ }^{2}$ Madhavbaug Cardiac Care Clinics, Pune, Maharashtra, India

Received: 11 June 2018

Accepted: 03 July 2018

*Correspondence to:

Dr. Rahul Mandole,

Email: cromilagro@gmail.com

Copyright: (C) the author(s), publisher and licensee Medip Academy. This is an openaccess article distributed under the terms of the Creative Commons Attribution NonCommercial License, which permits unrestricted noncommercial use, distribution, and reproduction in any medium, provided the original work is properly cited.

\begin{abstract}
Background: Number of people dying from IHD has increased from 0.61 million in 1990 to 1.13 million in 2010, which is a disturbing fact. According to report by World Health Organization, India would be spending a whopping 237 billion US dollars, owing to direct spending on health care and indirectly due to loss of productivity due to IHD. Ischemia Reversal Program (IRP) is a combination of Panchakarma and allied therapy. This study was conducted to evaluate the effect of IRP on VO2max, Duke's treadmill score, systolic blood pressure (SBP), diastolic blood pressure (DBP), and dependency on conventional therapy in IHD patients.
\end{abstract}

Methods: This observational study was conducted in January 2017, wherein the data of IHD patients (inducible ischemia on stress testing) who attended outpatient departments (OPDs) at Madhavbaug clinics in Maharashtra, India were identified. Data of patients who were administered IRP (60-75 minutes) with minimum 7 sittings over 90 days $( \pm 15$ days $)$ were considered. Variables were compared between day 1 and day 90 of the IRP.

Results: Out of 38 enrolled patients, 25 were males while 13 females. There was significant improvement in Duke's score with subjects at moderate $(50 \%)$ and high $(31.6 \%)$ risk at baseline were significantly decreased to low $(52.6 \%)$ and moderate $(47.4 \%)$ after the $90^{\text {th }}$ day of therapy. IRP also showed significant improvement in VO2max by 9.11 (from $20.29 \pm 6.72$ to $29.40 \pm 6.71$; $<<0.001$ ), SBP by 5.78 (from $128.78 \pm 17.40$ to $123 \pm 12.23$, p <0.03), DBP by 4.76 (from $80.53 \pm 8.10$ to $75.76 \pm 6.85, \mathrm{p}<0.005)$. Dependency on concomitant medicines was reduced.

Conclusions: IRP was effective in IHD; it had dual benefits, i.e. anti-ischemic effect, as well as reducing the dependency on allopathic medicines.

Keywords: Alternative medicine, Blood pressure, Diastolic, Ischemia reversal program, IRP, Ischemic heart disease, IHD, Panchakarma

\section{INTRODUCTION}

Cardiovascular diseases (CVDs) comprising of coronary artery disease in the form of ischemic heart disease (IHD) have scaled the prevalence rates to the figures that signify epidemic. Around 17.5 million deaths across the globe are due to CVDs. ${ }^{1}$ Worrisome fact is that three quarters of these deaths in developing countries alone. This is further complicated by the fact that, although the prevalence of deaths due to CVD is reducing in developed countries, it is creating a menace in developing nations like India, year after year. ${ }^{2}$ Epidemiological transition is attributed by some authors to such increased prevalence, which comprises of urbanization, lifestyle changes, etc. ${ }^{3}$ India is experiencing the age of obesity and inactivity, where sedentary lifestyle gives rise to diseases like lipid abnormalities, diabetes, IHD, HTN, which in turn increases morbidity and mortality in India, contributing to increased burden on healthcare and cost. ${ }^{4}$ The Global Burden of Disease study found that in past three decades 
there was doubling of morbidity and mortality due to CVD. ${ }^{5}$ Number of people dying from IHD has increased from 0.61 millions in 1990 to 1.13 millions in 2010, which is a disturbing fact. ${ }^{6}$ According to report by World Health Organization, India would be spending a whopping 237 billion US dollars, owing to direct spending on health care and indirectly due to loss of productivity due to IHD. ${ }^{7}$

IHD contributes maximum amongst deaths due to CVD in India $(>80 \%)$. This mortality rate is way higher than the global average mortality rate due to IHD. In India, IHD is the culprit for $1 / 5^{\text {th }}$ of all deaths $(21 \%)$ and $1 / 10^{\text {th }}$ of life years lost, which measures premature deaths by considering young deaths over old age. ${ }^{8}$

Low diagnosis rates, less adherence, reduced treatment adherence, less use of evidence based interventions are the major hurdles for optimal use of cost effective treatment on an extensive scale, in India. Poor adherence to medication, alone is the major culprit which causes increased morbidity and mortality in patients with IHD and also increases the cost of health care. ${ }^{9,10}$ Although there are various guidelines in place to combat the menace of IHD, still its prevalence is rising. This is complicated by low adherence to medications, which is due to adverse effects to medications, increased cost, etc. ${ }^{11}$ Hence, there is a need to explore new therapeutic option to effectively combat IHD.

Management of IHD is complex due to the role of various factors while deciding treatment plan like comorbidities, age, concomitant medication, etc. Hence, it is a vital demand of time to search for novel their alternative which will help to decrease anxiety and fear also with IHD and increase quality of life simultaneously. ${ }^{12}$ The therapeutic role of drugs used in the treatment of IHD is due to a correction of imbalance between oxygen demand and supply to the heart, reduction in blood pressure (BP), reducing platelet aggregation, hypolipidemic action, antioxidant effect, etc. ${ }^{13}$ Similar action has been found in numerous herbal drugs, which serve as interesting potential targets for newer therapeutic options for treatment of HTN. ${ }^{14-16}$
The Ayurveda practice of Medicine suggests the use of traditional drugs in the acute phase of disease, while adding "Panchakarma" therapy (internal body purification through multi-step process) in the chronic phase of disease. Ischemia Reversal Program (IRP) is a combination of Panchakarma and allied therapy. The techniques used in Panchakarma under this program are Swedana i.e. passive heat therapy, Snehana i.e. oleation and Basti i.e. per rectal drug administration. These techniques are widely recognized for their detoxification function. ${ }^{17,18}$ It has been found in a study that IHD is associated with anxiety, depression, reduced feeling of personal strength, reduced quality of life, etc. ${ }^{19}$ Hence, we planned an observational study to investigate the efficacy of IRP, as add-on therapy to standard anti-ischemic therapy in patients of IHD. We evaluated the effect of IRP on maximum oxygen consumption/maximum aerobic capacity measured by VO2max (V-volume, O2-oxygen, max-maximum), Duke's treadmill score, systolic (SBP) and diastolic BP (DBP), and dependency of these IHD patients on standard conventional medications.

\section{METHODS}

This was an observational study conducted between January 2017 to January 2018, wherein we identified the data of patients suffering from IHD (positive for inducible ischemia from stress test) of either gender and any age, and who had attended the out-patient departments (OPDs) at multiple Madhavbaug clinics located in various cities of Maharashtra, India. The data of patients who had been administered IRP with minimum 7 sittings over a span of 90 days ( \pm 15 days) were considered for the study. Cases were identified, and data were assessed from the records of Madhavbaug clinics in Maharashtra. The selection was based upon the availability of complete relevant baseline data (day 1 of IRP) and final day data (day 90 of IRP) of the patients.

The IRP is a 3-step procedure, which was performed on the patients of IHD after a light breakfast. One sitting of the procedure took 65-75 minutes, as described in Table $1 .^{18,20}$

Table 1: Study treatment: Ischemia Reversal Program (IRP Kit).

\begin{tabular}{|llll|}
\hline Step of IRP & Type of Therapy & Herbs used for therapy & Duration of Therapy \\
\hline Snehana & $\begin{array}{l}\text { Massage or external oleation } \\
\text { (centripetal upper strokes } \\
\text { directed towards heart) }\end{array}$ & $\begin{array}{l}100 \mathrm{ml} \text { [Sesame oil (80\%) + Lavender oil } \\
(20 \%)]\end{array}$ & $30-35$ minutes \\
\hline Swedana & Passive heat therapy & $\begin{array}{l}\text { Dashmoola (group of ten herbal roots) with } \\
\text { steam at } \leq 40 \text { degrees Celsius) }\end{array}$ & $\begin{array}{l}10-15 \text { minutes }+3-4 \\
\text { minutes of relaxation } \\
\text { after procedure }\end{array}$ \\
\hline Basti & $\begin{array}{l}\text { Per rectal drug administration } \\
\text { using a rectal solution. }\end{array}$ & Luke-warm GHA decoction 100ml & 15 minutes \\
\hline
\end{tabular}

On day 1 of IRP, the patients had undergone Duke's treadmill scoring, VO2max, SBP, DBP as per international recommendations. ${ }^{25}$ These readings were considered as baseline readings. This process was repeated on day 90 of 
the IRP to calculate \% change from baseline reading. The dependency on standard medication was calculated both on day 1 and day 90 of IRP as the percentage of patients out of the total enrolled ones who required a conventional allopathic therapeutic agent during the study period of 90 days. The patients followed a diet chart/plan of 1200 calories/day.

\section{Statistical analysis}

Data were pooled and coded in Microsoft Excel spreadsheet. R Version 3.4.1 software was used to analyze the data. Categorical data were represented in the frequency form and continuous data were presented as the Mean \pm SD. The McNemar-Bowker test was used to assess the Duke Treadmill Score before and after 90 days of treatment. The Paired t-test was used to assess the difference between baseline values and $90^{\text {th }}$ day after treatment. Box plot and histogram were used to represent the graphs

\section{RESULTS}

\section{Study population}

A total of 51 patients' data was screened for inclusion in the study. However, based on the availability of data (Day 1 and Day 90) and the inclusion criteria, 38 patients were selected, and their data were considered for analysis (Figure 1). The baseline characteristics of these patients are shown in Table 2.

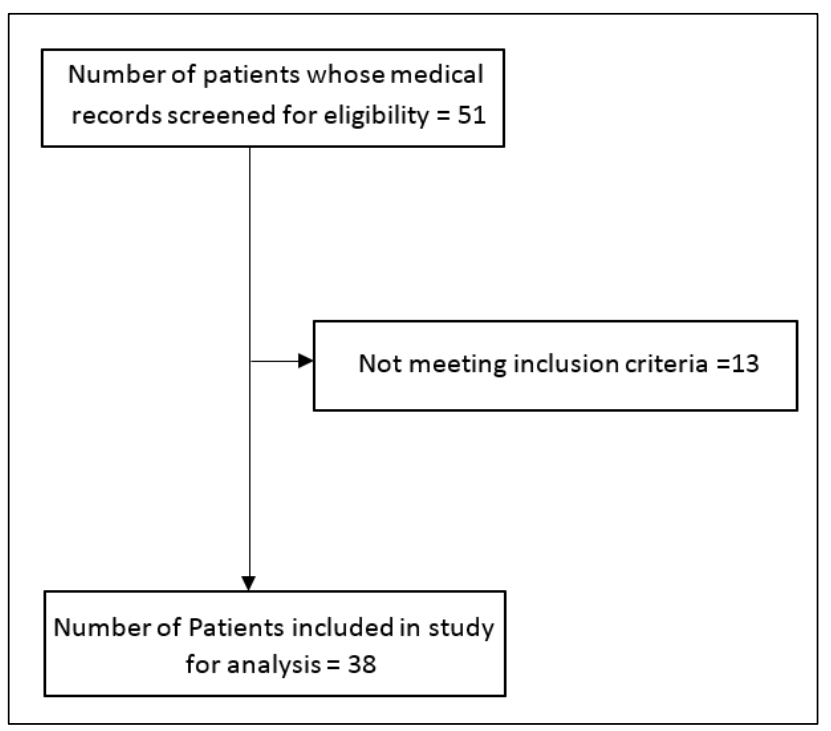

Figure 1: Patient enrolment flow chart.

Demographic characteristics of the subjects enrolled in the study was as shown in Table 2 . The present involved a total of 38 IHD patients. The mean age of the enrolled subjects was $55.21 \pm 9.27$ years. Nearly three-fourths of the study subjects were male $(65.79 \%)$. All the patients approached Panchakarma unit for Sarvanga Swedana during the study period. Among them, nearly three-fourths 27 (71.05\%) of the subjects approached Panchakarma unit for 7 settings.

Table 2: Baseline characteristics of the study subjects $(n=30)$.

\begin{tabular}{|ll|}
\hline Variable & $\mathbf{N}=\mathbf{3 8}$ \\
\hline Age (years) & $55.21 \pm 9.27$ \\
\hline Gender & \\
\hline Male & $25(65.79)$ \\
\hline Female & $13(34.21)$ \\
\hline
\end{tabular}

Data were expressed in $\%$ and mean \pm SD

Comparison of Duke's treadmill score baseline and after the 90 days of therapy was as shown in Table 3. At baseline, the subjects at moderate $(50 \%)$ and high $(31.6 \%)$ risk were significantly decreased to low (52.6\%) and moderate $(47.4 \%)$ after the $90^{\text {th }}$ day of therapy. Overall, after $90^{\text {th }}$ day, no cases of high risk were reported.

Table 3: Comparison of Duke treadmill score baseline and after 90 days of treatment $(n=38)$.

\begin{tabular}{|c|c|c|c|c|c|c|}
\hline \multirow{2}{*}{\multicolumn{2}{|c|}{$\begin{array}{l}\text { Duke } \\
\text { treadmill } \\
\text { score }\end{array}$}} & \multicolumn{3}{|c|}{ After 90 days } & \multirow{2}{*}{ Total } & \multirow[b]{2}{*}{ p-value } \\
\hline & & Low & Moderate & High & & \\
\hline \multirow{3}{*}{$\begin{array}{l}\text { Base } \\
\text {-line } \\
\left(1^{\text {st }}\right. \\
\text { day) }\end{array}$} & Low & 6 & 1 & 0 & $\begin{array}{l}7 \\
(18.4 \%)\end{array}$ & \multirow{4}{*}{0.0001} \\
\hline & $\begin{array}{l}\text { Mod- } \\
\text { erate }\end{array}$ & 11 & 8 & 0 & $\begin{array}{l}19 \\
(50 \%)\end{array}$ & \\
\hline & High & 3 & 9 & 0 & $\begin{array}{l}12 \\
(31.6 \%)\end{array}$ & \\
\hline \multicolumn{2}{|l|}{ Total } & $\begin{array}{l}20 \\
(53 \%)\end{array}$ & $\begin{array}{l}18 \\
(47.4 \%)\end{array}$ & 0 & $\begin{array}{l}38 \\
(100 \%)\end{array}$ & \\
\hline
\end{tabular}

* indicates high statistically significant improvement

Table 4: Comparison of clinical parameters between baseline values and 90th day.

\begin{tabular}{|llcll|}
$\begin{array}{l}\text { Variable } \\
\text { n=38 }\end{array}$ & Baseline & $\begin{array}{c}\text { After 90 } \\
\text { days }\end{array}$ & $\begin{array}{l}\text { Differ- } \\
\text { ence }\end{array}$ & $\begin{array}{l}\mathbf{p} \\
\text { value }\end{array}$ \\
\hline VO2.max & $20.29 \pm 6.72$ & $29.40 \pm 6.71$ & -9.11026 & $<0.001$ \\
\hline SBP & $128.78 \pm 17.4$ & $123 \pm 12.23$ & 5.789474 & 0.03 \\
\hline DBP & $80.53 \pm 8.10$ & $75.76 \pm 6.85$ & 4.76 & 0.005 \\
\hline
\end{tabular}

VO2.max, Maximum amount of oxygen consumption; SBP, Systolic blood pressure; DBP, Diastolic blood pressure

Clinical parameters compared between baseline values and after the $90^{\text {th }}$ day was as shown in Table 4 . The maximum amount of oxygen consumption was significantly improved after $90^{\text {th }}$ day of therapy $(\mathrm{P}<0.001)$ Figure 3 . Systolic blood pressure was significantly attained near normal value after $90^{\text {th }}$ day of therapy $(\mathrm{P}<0.03)$ Figure 4. Although, diastolic blood pressure which was normal before the therapy reduced significantly, it was within the normal range $(\mathrm{P}<0.005)$ Figure 5.

Allopathic medicines consumption on day 1 and after $90^{\text {th }}$ day of therapy were as shown in Table 5. Most of the enrolled IHD subjects were treated with biguanides $(34.21 \%)$, statins $(47.37 \%)$, beta blockers $(34.21 \%)$, 
antiplatelets (39.47), angiotensin II receptor blockers (26.32) and nonsteroidal anti-inflammatory drugs (60.53). All the subjects who were allopathic medicines before therapy was decreased after the $90^{\text {th }}$ day. However, the subjects with absence of medication history was not varied after the therapy. An illustration is given in Figure 6.

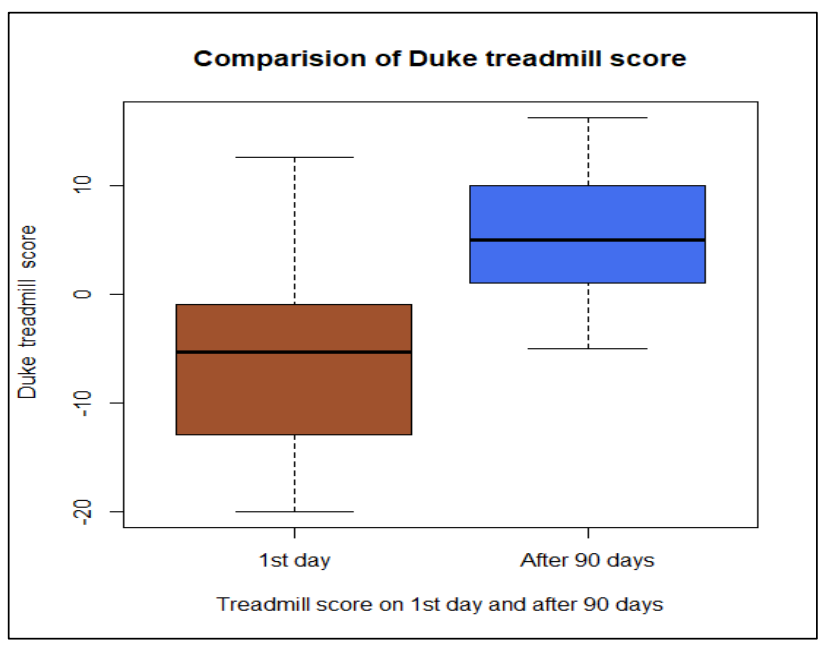

Figure 2: Comparison of Duke treadmill score baseline and after 90 days of treatment $(n=38)$.

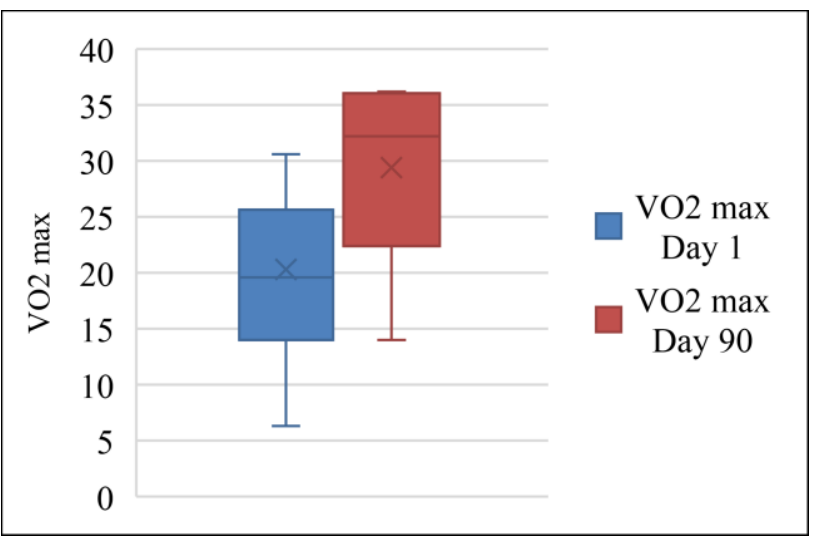

Figure 3: Comparison of clinical parameters between baseline values and $90^{\text {th }}$ day.

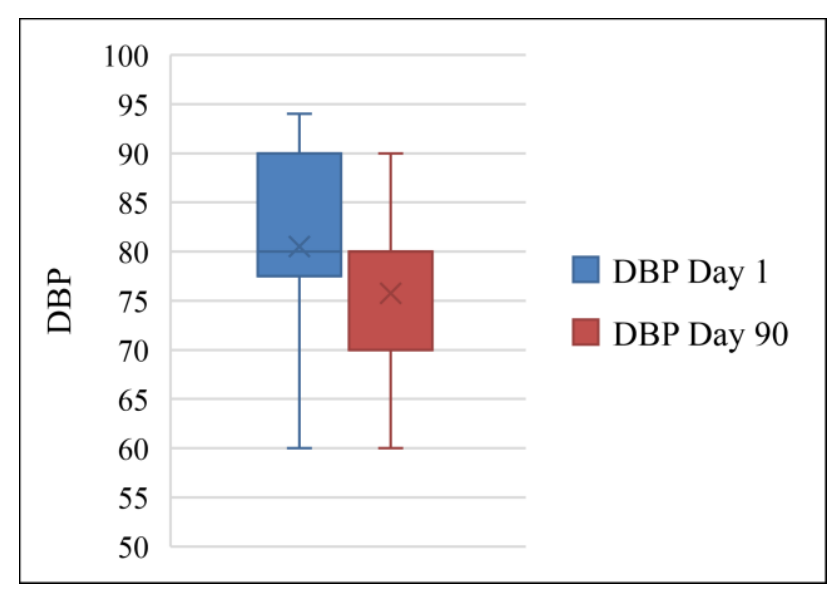

Figure 4: Comparison of SBP.

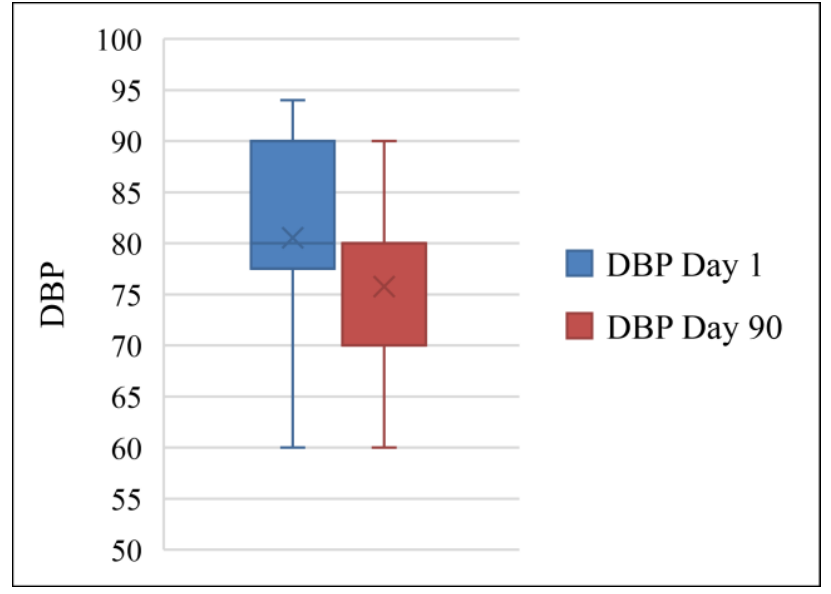

Figure 5: Comparison of DBP.

Table 5: Comparison of consumption of allopathy medicines at day 1 and after 90 days.

\begin{tabular}{|lll|}
\hline Medicine & Baseline & After 90 days \\
\hline NSAID + antiplatelet & $1(2.63)$ & $0(0)$ \\
\hline Diuretic & $4(10.53)$ & $2(5.26)$ \\
\hline ACE & $3(7.89)$ & $2(5.26)$ \\
\hline Statin & $18(47.37)$ & $12(31.58)$ \\
\hline CCB & $5(13.16)$ & $3(7.89)$ \\
\hline Beta blocker & $13(34.21)$ & $8(21.05)$ \\
\hline Antiplatelet & $15(39.47)$ & $12(31.58)$ \\
\hline ARB & $10(26.32)$ & $7(18.42)$ \\
\hline NSAID & $23(60.53)$ & $17(44.74)$ \\
\hline Sulfonylurea & $7(18.42)$ & $5(13.16)$ \\
\hline Biguanide & $13(34.21)$ & $8(21.05)$ \\
\hline No Medicine & $3(7.89)$ & $3(7.89)$ \\
\hline
\end{tabular}

CCB, Calcium channel blockers; ARB, Angiotensin II receptor blockers; NSAID, Nonsteroidal anti-inflammatory drugs

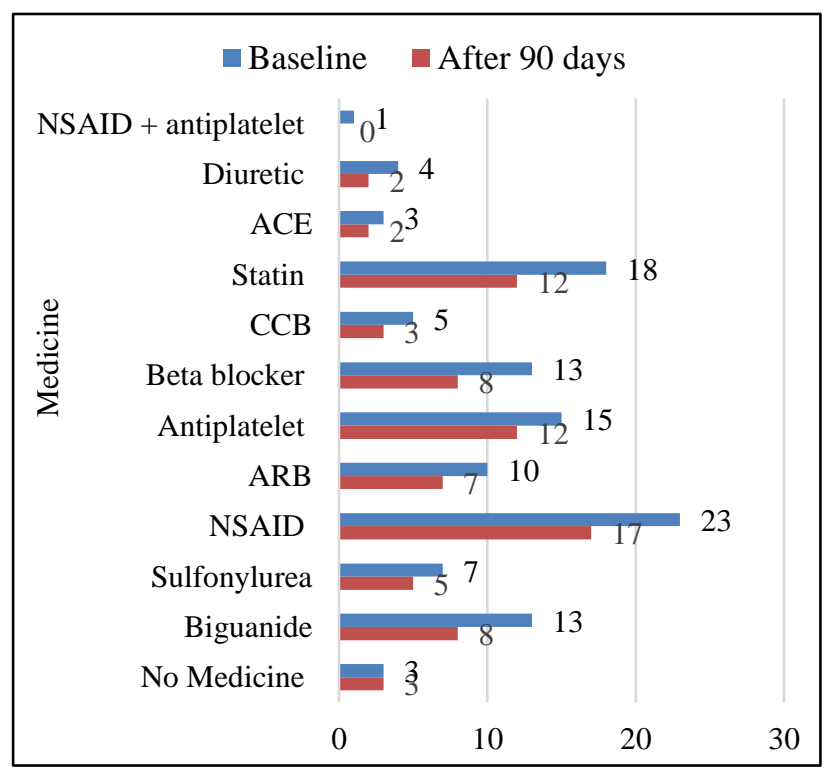

Figure 6: Comparison of consumption of allopathy medicine at 1st day and after 90 days. 


\section{DISCUSSION}

Despite the availability of the plethora of the options for treatment of IHD, it is still amongst leading contributor to global morbidity and mortality rates. Thus, it is dire need of the time to look out for new therapeutic option for treatment of IHD. Traditional class of anti-ischemic drugs have therapeutic benefit in IHD by correction of imbalance between oxygen demand and supply to the heart, reduction in blood pressure (BP), reducing platelet aggregation, hypolipidemic action, antioxidant effect, etc. Similar property has been found in various herbal drugs, thus making Ayurveda a potent and viable alternative to standard therapy in the management of IHD. Panchakarma is administered as add on therapy for IHD management, by Ayurveda physicians. ${ }^{20}$ IRP is a 3 step procedure consisting of Snehana, Swedana, and Basti. Probable mode of action of IRP is Snehana-anxiolytic reduces sympathetic over activity Swedana- reduces sodium and fluid that reduces resting preload that may help to reduce myocardial oxygen demand. Decoction of Tribulus terristris, curcumin and Phyllanthrus embelica can be helpful for nitric oxide liberation from endothelium. Along with it can be anti-inflammatory and antioxidant. This action may be helpful in improving coronary circulation by causing coronary vasodilation. ${ }^{17,20,22-24,26}$ In pursuit of analyzing the efficacy of the IRP in IHD, we found that it showed significant (very high statistical significance) improvement in VO2max, Duke's treadmill score, DBP, and SBP (high statistical significance) at the $90^{\text {th }}$ day of the whole procedure. SBP is one of the prognostic marker for patients of IHD. Reduction in SBP is associated with better prognosis in IHD, since it reduces afterload of the ventricles and also improves endothelial health. ${ }^{27}$ Most importantly, we found that IRP noticeably reduced patient's dependency on standard allopathic medication at the end of 90 days of therapy.

VO2max measures the maximum oxygen hat can be utilized during exercise. IHD patient suffers from diastolic dysfunction, hence VO2max is reduced in such cases which manifests clinically as reduced exercise/work capacity. ${ }^{27}$ Duke's treadmill score is used as diagnostic and prognostic investigation in risk patients of IHD. It is favoured more for its risk stratification role. It is calculated by the following formula:

Duke treadmill score $=$ maximum exercise time in minutes $-5 \times \mathrm{ST}$ segment deviation in $\mathrm{mm}-4 \times$ angina index

where $0=$ no angina, $1=$ non-limiting angina, $2=$ exercise limiting angina.

Duke's treadmill score $\geq 5$ signifies low risk for cardiovascular complication and these people do not need coronary angiography for further evaluation. Their 4 year survival rate is almost $100 \%$. Duke's score <-11 denotes a high risk group and these patients need coronary angiography for further evaluation. Their 4- year survival rates are $79 \%$. A score below +4 and -10 signify intermediate risk group. These patients require either coronary angiography or myocardial perfusion scan for evaluation, depending on patient status. ${ }^{25}$ In our study, both VO2max and Duke's treadmill score were significant (high statistical significance) improved. Studies show that improvement in Duke's score and VO2max are associated with better prognosis in IHD patients. ${ }^{25,27,28}$ Hence, significant reduction in VO2max and Duke's treadmill score after IRP in our study indicates favourable prognosis in cardiovascular morbidity and mortality.

In economically constraint countries like India the high dependence of IHD patients on conventional allopathic medication escalates the healthcare cost many fold. Furthermore, increased adverse effect of these drugs lead to decreased adherence, which further worsens the picture. ${ }^{12}$ Keeping this in mind, we analyzed changes in patients' dependency on allopathic medication by IRP. There was significant reduction in dependency on almost all the class of anti-ischemic drugs, at the end of 90 days, with an increase in the number of patients who went off the allopathic drugs.

The findings of the present study can be generalized only after a comparison with the findings of other such studies with probably prospective design, larger sample size, one more arm with standard therapy alone and more follow up period. This will help in identifying long term outcomes of IRP in the management of IHD.

\section{CONCLUSION}

There was significant improvement in VO2max, Duke's treadmill score, SBP, DBP after IRP. Also, there was substantive attenuation in patient's dependency on allopathic medications. Hence, the IRP may serve as a potent and viable alternative to standard allopathic treatment of IHD.

\section{ACKNOWLEDGEMENTS}

Authors would like to thank the study participants and their families, without whom this study would not have been accomplished.

Funding: Vaidya Sane Ayurvedic Education and Agricultural Research Trusts

Conflict of interest: None declared

Ethical approval: The study was approved by the Institutional Ethics Committee

\section{REFERENCES}

1. World Health Organization. Global Status Report on Non-Communicable Diseases 2014. Geneva, Switzerland: World Health Organization; 2014.

2. Fuster V, Kelly B. Board for global health. Promoting cardiovascular health in developing world: a critical challenge to achieve global health. Washington, DC: Institutes of Medicine; 2010. 
3. Gaziano T, Gaziano J. Epidemiology of cardiovascular disease. In: Harrison's Principles of Internal Medicine. 19th ed. New York, NY: McGraw Hill;2016:266.e1e5.

4. Gupta R, Guptha S, Sharma KK, Gupta A, Deedwania P. Regional variations in cardiovascular risk factors in India: India heart watch. World J Cardiol. 2012 Apr 26;4(4):112

5. Forouzanfar MH, Moran AE, Flaxman AD, Roth G, Mensah GA, Ezzati M, et al. Assessing the global burden of ischemic heart disease, part 2: analytic methods and estimates of the global epidemiology of ischemic heart disease in 2010. Global Heart. 2012;7:331e42.

6. Global Burden of Diseases 2013 Mortality and Causes of Death Collaborators. Global, regional, and national levels of age-sex specific all-cause and cause-specific mortality for 240 causes of death, 1990-2013: a systematic analysis for the Global Burden of Disease Study 2013. Lancet. 2015;385:117e71.

7. World Health Organization. Global atlas on cardiovascular disease prevention and control. Geneva, Switzerland; 2011. Available from: http://www.who.int/cardiovascular_diseases/publicati ons/atlas_cvd/en/.

8. GBD Profile: India. Institute of Health Metrics and Evaluation. Available from: http://www.healthdata.org/sites/default/files/files/cou ntry_profiles/GBD/ihme_gbd_country_report_india.p df. Accessed April 30, 2014.

9. Al-Lawati S. A report on patient non-adherence in Ireland. Dublin:Pfizer;2014.

10. O'Connor P. Improving medication adherence: challenges for physicians, payers, and policy makers. Arch Intern Med. 2006;166:1802-4.

11. Kolandaivelu K, Leiden BB, O'gara PT, Bhatt DL. Non-adherence to cardiovascular medications. European heart journal. 2014 Sep 29;35(46):3267-76.

12. Gupta R, Mohan I, Narula J. Trends in coronary heart disease epidemiology in India. Annals of global health. 2016 Mar 1;82(2):307-15.

13. Al-Nimer MS. Evaluation of anti-ischemic therapy in coronary artery disease: a review. In Coronary Artery Diseases 2012. InTech. Available from: http://www.intechopen.com/books/coronary-arterydiseases/evaluation-of-anti-ischemic-therapy-incoronaryartery disease-a-review.

14. Gui QF, Xu ZR, Xu KY, Yang YM. The efficacy of ginseng-related therapies in type 2 diabetes mellitus: an updated systematic review and meta-analysis. Medicine. 2016 Feb;95(6).

15. Huang H, Lai S, Wan Q, Qi W, Liu J. Astragaloside IV protects cardiomyocytes from anoxia/reoxygenation injury by upregulating the expression of Hes1 protein. Canadian $\mathrm{J}$ physiology and pharmacol. 2015 Dec 16;94(5):542-53.

16. Fleming J, Kris-Etherton P. The evidence for alinolenic acid and cardiovascular disease benefits: comparisons with eicosapentaenoic acid and docosahexaenoic acid. Adv Nutr. 2014;5:863S-76S.

17. Choudhary K, Sharma P, Sharma V. Hypertension and its management through Panchakarma, J of Ayurveda and Hol Med. 2015;3(3):28-31.

18. Uebaba K, Xu FH, Ogawa H, Tatsuse T, Wang BH, Hisajima $\mathrm{T}$, Venkatraman $\mathrm{S}$. Psychoneuroimmunologic effects of Ayurvedic oildripping treatment. J alternative complementary Med. 2008 Dec 1;14(10):1189-98.

19. Taghadosi M, Arani Z, Gilani H. Quality of life in patients with ischemic heart disease. J Nursing Midwifery Sci. 2014:1(1):19-26

20. Sane R, Aklujkar A, Patil A, Mandole R. Effect of heart failure reversal treatment as add-on therapy in patients with chronic heart failure: A randomized, open-label study. Indian Heart J. 2017;69(3):299-304.

21. Liperoti R, Vetrano DL, Bernabei R, Onder G. Herbal medications in cardiovascular medicine. J American Coll Cardiol. 2017 Feb 27;69(9):1188-99.

22. Zhang S, Li H, Yang S. Tribulosin protects rat hearts from ischemia/reperfusion injury. Acta Pharmacologica Sinica. 2010;31(6):671-78.

23. Bhattacharjee S, Banerjee N, Chatterjee S, Santra T, Chatterjee S, Chatterjee A, et al. Role of turmeric in management of different non-communicable diseases. World J Pharm Pharm Sci. 2017 May 20;6:1767-78.

24. Gopa B, Bhatt J, Hemavathi K. A comparative clinical study of hypolipidemic efficacy of Amla (Emblica officinalis) with 3-hydroxy-3-methylglutarylcoenzyme-A reductase inhibitor simvastatin. Indian $\mathbf{J}$ Pharmacology. 2012;44(2):238-42.

25. Lairikyengbam S, Davies A. Interpreting exercise treadmill tests needs scoring system. BMJ. 2002;325(7361):443.

26. Chhatre S, Nesari T, Somani G, Kanchan D, Sathaye S. Phytopharmacological overview of Tribulus terrestris. Pharmacognosy reviews. 2014 Jan;8(15):45.

27. Lele SS, Macfarlane D, Morrison S, Thomson H, Khafagi F, Frenneaux M. Determinants of exercise capacity in patients with coronary artery disease and mild to moderate systolic dysfunction: Role of heart rate and diastolic filling abnormalities. European heart J. 1996 Feb 1;17(2):204-12.

28. César MD, Montesano FT, Diniz RV, Almeida DR, Tebexreni AS, Barros TL. Cardiopulmonary responses to exercise in patients of different age group with congestive heart failure. Arquivos brasileiros de cardiologia. 2006 Jan;86(1):14-8.

Cite this article as: Sane R, Sugwekar V, Nadapude A, Hande A, Depe G, Mandole R. Study of efficacy of ischemia reversal program (IRP) in ischemic heart disease (IHD) patients with VO2max and Duke's treadmill score. Int J Basic Clin Pharmacol 2018;7:1642-7. 